Ein Verfahren zur Auflösung des geglühten Eisenoxydes und anderer Metalloxyde.

(Briefliche Mittheilung.)

Von

\title{
Hugo Bornträger,
}

Fabrikdirector.

Bekanntlich kommt man bei der Analyse oft in die Lage, geglühte Metalloxyde, zum Beispiel Eisenoxyd, nochmals lösen zu müssen. Die meisten Verfahren zu diesem Zwecke sind umständlich und zeitraubend, weshalb ich ein einfaches kurz mittheile.

Man entwickelt aus Salzsäure und gewogenem Blumendraht Wasserstoff und trägt das Oxyd in diese Entwicklung ein. Das Oxyd löst sich momentan auf, indem der Wasserstoff in statu nascendi es sofort zu Oxydul reducirt.

Selbstredend gilt dies für viele Metalloxyde.

Ob man das Verfahren benutzen kann, um in den Kiesabbränden den Schwefel zu bestimmen, habe ich noch nicht feststellen können, da mir Zeit und Material dazu fehlen.

Obermendig a. Laacher See.

\section{Mittheilungen aus dem chemischen Laboratorium des Prof. Dr. R. Fresenius zu Wiesbaden.}

Deber eigenthümliche Löslichkeitsverhältnisse des schwefelsauren Baryts.

$$
\text { Von }
$$

\section{R. Fresenius und E. Hintz.}

Die Angaben über die Löslichkeit des schwefelsauren Baryts in Wasser, welche die Litteratur aufweist, weichen ausserordentlich von einander ab. Als Belege mögen folgende dienen: In Berzelius, Lehrbuch der Chemie, deutsch von Wöhler 4, 241 (1835) heisst es, er sei in Wasser unlöslich, - in L. Gmelin's Handbuch der Chemie, 4. Auflage (1848) flndet sich die Angabe, er brauche 43000 'Theile 